\title{
Mine Closure and Ecosystem Development —Alcan Gove Bauxite Mine, Northern Territory, Australia
}

\author{
A.V. Spain School of Earth Sciences, James Cook University, Australia \\ D.A. Hinz MatrixPlus Consulting, Australia
}

J.A. Ludwig CSIRO Sustainable Ecosystems, Australia

M. Tibbett Centre for Land Rehabilitation, The University of Western Australia, Australia

D.J. Tongway School of Resources, Environment and Society, Australian National University, Australia

\section{INTRODUCTION}

Closure is a critical phase of a mining operation since this is when the environmental effects of mining and rehabilitation works will be most stringently judged. Since the time scales required for biological community development and soil formation are long in comparison to mining operation life cycles - and to human life spans - it is normally only possible to demonstrate the early trajectories of these processes. However, favourable and predictable closure outcomes can usually be achieved by making early decisions on postmining land use, ensuring close integration of mining with incremental rehabilitation works and adequate monitoring. This assumes that a successful system of rehabilitation is available for the materials and environments involved and takes no account of threats or stressors.

This paper defines the stages of early post-rehabilitation ecosystem and soil development on highlyweathered soil materials at the Alcan Gove Mine using information derived from studies of selected sites from a 26-year chronosequence of sites and local native forest sites. Specifically, we seek to determine the stage at which a high probability of successful ongoing development may be credibly assumed in the absence of further management inputs of energy and materials and in relationship to potential external threats.

\section{SITE CHARACTERISTICS AND METHODS}

Gove is located in the seasonally humid tropics and c. $70 \%$ of annual rainfall occurs within the months of December to March (Table 1). Annual pan evaporation substantially exceeds precipitation. Local soils are highly weathered and extremely permeable; their clay-sized materials are dominated by kaolinite and the oxides of Fe and Al. Native vegetation communities comprise three-tiers: a tall tree canopy dominated by Eucalyptus tetrodonta and Eucalyptus miniata, a small tree-shrub layer and an herbaceous layer dominated by perennial grasses.

Cultural, biological and economic factors were considered in the setting of rehabilitation goals (Hinz, 1992). The mining area is leased from the aboriginal owners and it was their stated requirement to have the mined lands returned to native forest of similar structure and composition to that present before mining. This included the requirement that the upper stratum of the forest is dominated by Eucalyptus tetrodonta, a species of great spiritual, medicinal and practical value to the traditional owners (Hinz, 1992). Other species are also valued and must be present in the rehabilitated mine ecosystems.

From all stakeholders' viewpoints, the newly created ecosystems must also be capable of undergoing successional processes such that they increasingly resemble the local native communities. They must also be sustainable: this implies that the restored ecosystems should have the capacity to resist the effects of such stressors as fires, cyclones, pest and disease outbreaks, be resilient to the damage that does occur and to be able to replace themselves without subsequent inputs of energy or materials.

Mining at Gove is integrated with a consistent, long-established system of rehabilitation (O'Keefe, 1992) and includes the following sequential processes (Hinz, 1992). The original forest is cleared, burned and then left for c. two years. The surface soil $(150 \mathrm{~mm})$ is then harvested to be applied as a surface layer on a separate, 
newly-rehabilitated site. The remaining soil is stockpiled while the site is mined. After mining, stockpiled soil is applied to the site surface, the site is ripped and surface soil from another site is applied. The seed of up to 20 species of local provenance tree and shrubs is sown; grass seed and fertilizer are applied after light surface cultivation. Between 18 and $25 \mathrm{~kg} \mathrm{ha}^{-1}$ of $\mathrm{P}$ is applied as single superphosphate. Of particular note is the deliberate exclusion of fire from all rehabilitated sites.

Information used in the present paper was derived largely from chronosequence studies carried out at the Alcan Gove Mine over the period 1991 to 2004. Aspects of this work have been described by Reddell et al. (1992, 1993), Tongway and Hindley (2003) and Spain et al. (2005). The work was conducted on an interdisciplinary basis and was integrated by using common study sites and locations within study sites, where the scales of the different studies permitted this. Studies were conducted of the major features of plant community development, litters, soils, soil and litter fauna and microbiota. Mainly static measures were taken although some seasonal contrasts were also made.

Table 1 Environmental characteristics of the Alcan Gove Mine site $\left(12^{\circ} 16^{\prime} \mathrm{S}, 1^{136^{\circ}}\right.$ 51'E), Gove Peninsula, Northern Territory, Australia

\begin{tabular}{|l|l|}
\hline Mean annual precipitation & $1444 \mathrm{~mm}$, summer maximum \\
\hline Annual pan evaporation & $2153 \mathrm{~mm}$ \\
\hline Temperatures & $32^{\circ} \mathrm{C}(\mathrm{Jan}), 27.8^{\circ} \mathrm{C}$ (July) \\
\hline Mean daily maxima & $24.6^{\circ} \mathrm{C}(\mathrm{Jan}), 19.2^{\circ} \mathrm{C}($ Aug $)$ \\
\hline Mean daily minima & $\begin{array}{l}\text { Oxisol (Soil Taxonomy) } \\
\text { Kandosol (Australian Soil Classification) }\end{array}$ \\
\hline Soil classification & Tall open forest \\
\hline Plant community structure &
\end{tabular}

\section{STUDY OUTCOMES}

The results are presented in terms of the developmental trajectories of the major ecosystem components over the 26-year chronosequence of study sites and in relation to the actual and potential stressors perceived as most relevant to rehabilitation success.

\subsection{Plant Community Development}

The plant communities of the rehabilitated sites undergo consistent and predictable changes with period of rehabilitation. Grasses initially dominated at the younger sites (with maximum basal area occurring at c. 3 years) but declined with increasing period of rehabilitation. Figure 1 presents site mean values for the rehabilitated and local unmined forest sites and suggested relationships with rehabilitation period. Stem population densities (Figure 1a) increased over the whole chronosequence and tree heights (Figure 1b) also increased consistently. Both attained values in the upper range of the native forest sites growing on the most widespread soils of the surrounding area although stem densities greater than c. 800 ha $^{-1}$ typically only occurred in native forests growing on very shallow soils. Unmined native forests on some deeper soils are taller - up to c. 30 m (Reddell et al., 1992) - than indicated in Figure 1b. Prior to canopy closure, Acacia species briefly dominated the tree stratum in terms of population density, height and, more transiently, basal area per plot. Canopy closure occurred between the ages of 9 to 12 years, after which the eucalypts increasingly dominated the tree stratum and the acacias declined in terms of both numbers and basal areas. The trajectory of maximum total plot basal area is approximately sigmoid over the 26-year chronosequence and, at the oldest sites, attains values similar to or greater than those of the native forest reference sites (Figure 1c). The change in dominance from acacias to eucalypts after canopy closure is illustrated by the 
differing progressions of basal areas attributable to the each genus (Figure 1c). The three-tiered structure of the local native forests was attained by 20 years and the upper stratum is largely dominated by E. tetrodonta and E. miniata. As illustrated in Figure 1d, E. tetrodonta comprises substantial percentages of both total basal area and the basal areas of the eucalypts. Basal areas of eucalypts were low in the plot rehabilitated for 26 years.

Throughout the chronosequence of sites, the understorey is dominated by Acacia spp., largely A. leptocarpa and A. aulacocarpa, although other genera of shrubs and small trees (Grevillea, Brachychiton, etc.) were also common. Grasses initially sown include Chloris gayana and a sterile Sorghum sp. although these are largely replaced by perennial native grasses relatively early in the chronosequence. However, the exotic grass Melinis repens occurs in low densities throughout the chronosequence of sites.

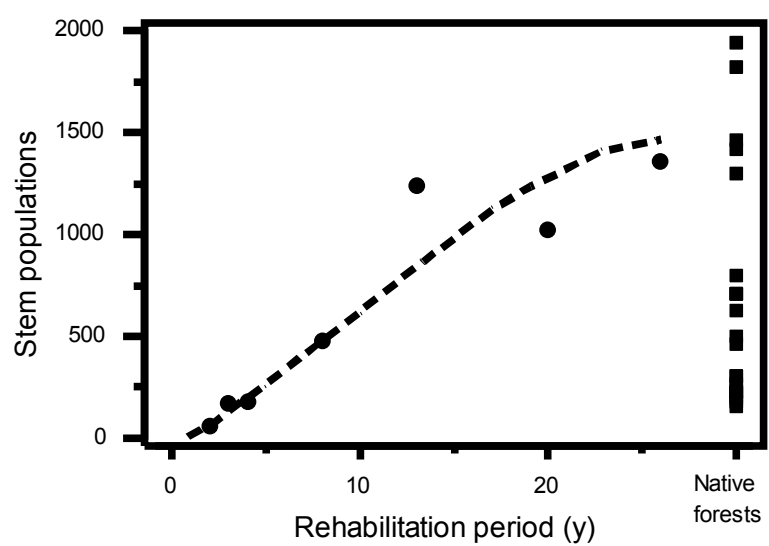

(a)

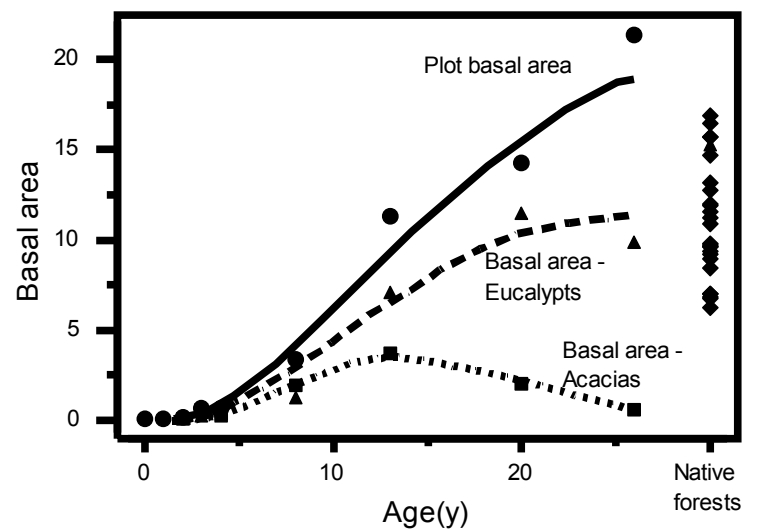

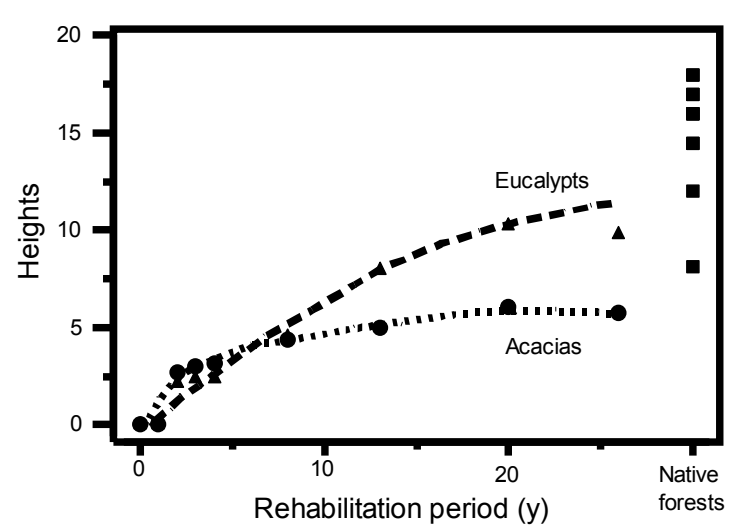

(b)

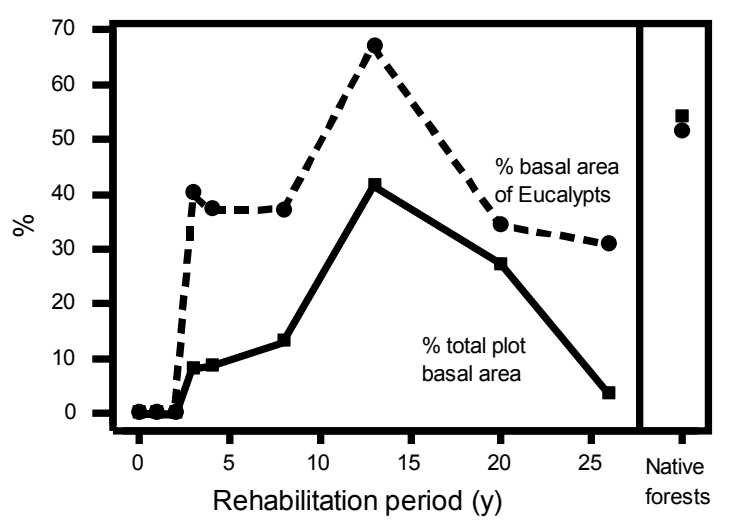

(d)

Figure 1 Site mean values and suggested patterns in selected plant community characteristics in a chronosequence of rehabilitated sites and in nearby unmined native forests (a) Population stem densities (stems ha ${ }^{-1}$ ); (b) Mean heights (m); (c) Total basal areas and basal areas of eucalypts and acacias $\left(\mathrm{m}^{2} \mathrm{ha}^{-1}\right)$; (d) Basal areas of $E$. tetrodonta as a percentage of total plot basal area and as a percentage of the basal area of eucalypts. Data presented are based on individuals taller than $1.5 \mathrm{~m}$ and with woody stems greater than $1 \mathrm{~cm}$ in diameter at $1.5 \mathrm{~m}$

\subsection{Litter Layer Development}

Surface coverage by standing and fallen fine litter (Figure 2a) increased rapidly in the early years of the chronosequence while litter mass (Figure $2 b$ ) increased more steadily. Site surfaces were largely protected from rain splash erosion by a combined coverage by herbaceous plants and litter of more than $60 \%$ at approximately three to four years after seeding; near-complete coverage was achieved shortly after canopy closure (Figure 2a). Litter dry mass in the unburned rehabilitated sites increased rapidly to mean maximum 
values nearly three times those of the local unmined forests; these forests had values typical of frequentlyburned Australian tropical savannas (Williams et al., 2002). Litter dry mass values after the wet season were slightly lower than in the late dry season, due to the higher decomposition rates that pertain over the wet season.

Litter compositional changes reflected plant community development. Figure $2 \mathrm{c}$ contrasts the median values of ranked observations made at sites along the chronosequence with values from local unmined forests. In the early years, litter was dominated by standing dead grasses; it later comprised a loose layer of mixed dead grasses and broad-leaved foliage, dominated by Acacia phyllodes. After canopy closure, the litter layer starts to develop a woodland character with a clear layering in which the current year's litter overlies moredecomposed materials at depth; the latter materials comprise the residua of the previous years' litters. During this period, the litter layers become dominated by Eucalypt foliage, with declining proportions of grasses and Acacia phyllodes. However, even at 26 years, the litter layers of the rehabilitated sites contain a wider range of the foliage of broad-leaved species than the regularly burned native forests.

Three measures of litter quality are their $\mathrm{C}$ concentrations, $\mathrm{C}: \mathrm{N}$ ratios and $\delta^{15} \mathrm{~N}$ values. All measures changed substantially during development with the differing materials acquired and the changing physical and chemical conditions in the accumulating litter layers. After canopy closure, the upper layer had similar C concentrations to those of plant materials while the lower layer materials had lesser values consistent with dust influx and the activities of soil animals in admixing litter and soil materials (Figure 2d). The C:N ratios of the litter layers (Figure 2e) are similar to those reported for Eucalypt-dominated litters elsewhere in Australia (calculated from $\mathrm{N}$ concentrations given by Bevege (1978) and assuming that the litters contained $43 \% \mathrm{C}$ ); the lesser values of the lower layer materials evidence their more decomposed state. $\delta^{15} \mathrm{~N}$ ratios indicate the greater degree of decomposition in the lower litter layer (Figure 2f).

\subsection{Soil Development}

Soil development is here considered as the improvement that occurs in physical, chemical and biological properties, as the soil reorganises and acquires fertility with increasing rehabilitation period. As with recently-restored soils elsewhere, those of the Gove post-mining environment are incipient at best and are therefore likely to be poorly conservative of the limited stocks of nutrient elements available, at least initially (Odum, 1969). Continuing soil development is therefore necessary to conserve ecosystem nutrient balances and is thus essential for self-sustainability. The following sections illustrate the major changes that occur.

\subsubsection{Physical fertility}

The restored soils of the Alcan Gove mine are developing on permeable (Figure 3a) pisolitic, gravel-rich (Figure $3 b$ ) and highly-weathered soil materials. The high permeability of these materials is probably a partial consequence of the high gravel content of the restored profiles and a characteristic micro-aggregation. Permeability continued to increase place along the chronosequence of sites with the ongoing structural development taking. This is considered to result from re-organisation of the upper profile through the joint action of physical processes and biological agents, largely social insects. Gravel contents in the unmined native forest soils declined with depth in the deep profile but increased in the shallower soil. The modal texture class of the fine earth fraction of the soil is a clay loam.

\subsubsection{Chemical fertility}

Chemical fertility includes such controlling factors as $\mathrm{pH}$, salinity, sodicity, nutrient element status and form and the concentration and quality of the soil organic matter that regulates the supply and retention of nutrient and other elements. It may also include the negative influences of toxic concentrations of metals and other elements, where these occur.

\subsubsection{Standard measures of fertility}

Soil $\mathrm{pH}\left(0.01 \mathrm{M} \mathrm{CaCl}_{2}, 1: 5\right)$ in the rehabilitated sites ranged from 4.89 to 6.00 , with slightly higher values in some native forest sites. These soils therefore lie above the $\mathrm{pH}$ range within which acid soil problems such as Al toxicity may be expected (Kabata and Kabata-Pendias, 2001). In these soils, pH change is poorly buffered 
and declined with increasing soil $\mathrm{C}$ concentration (Figure 4a): it is therefore lowest in the highly organic, near-surface soils of the longer rehabilitated sites.

(a)

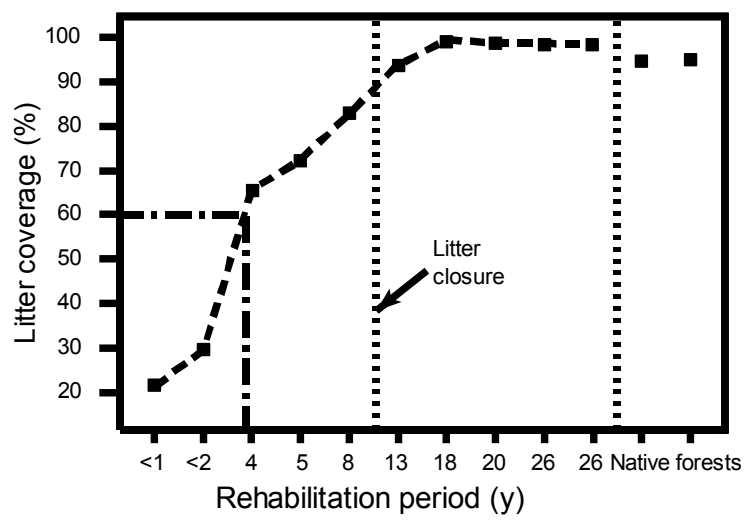

(c)

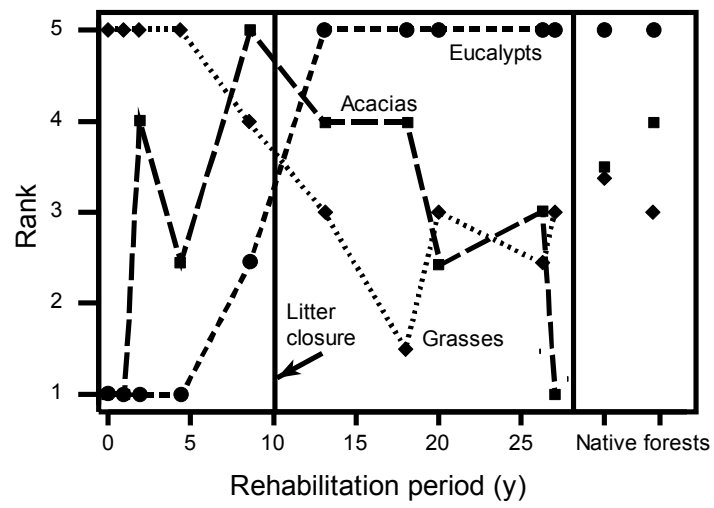

(e)

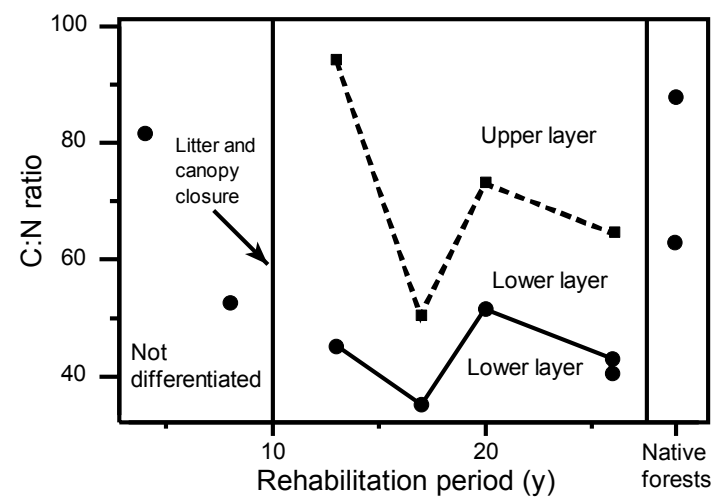

(b)

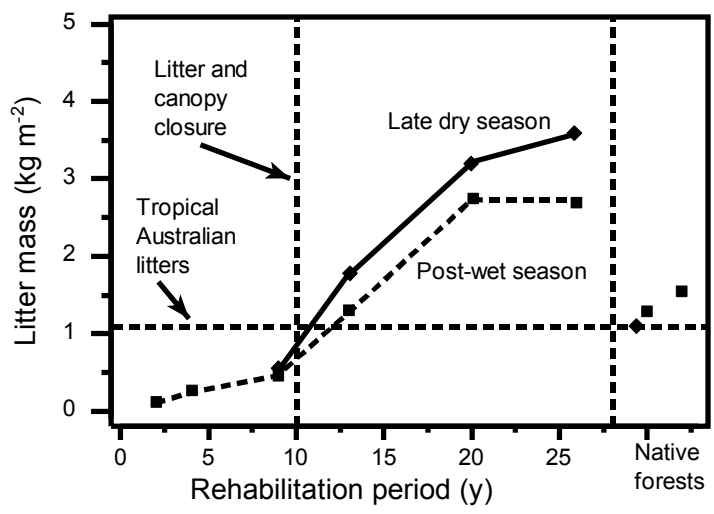

(d)

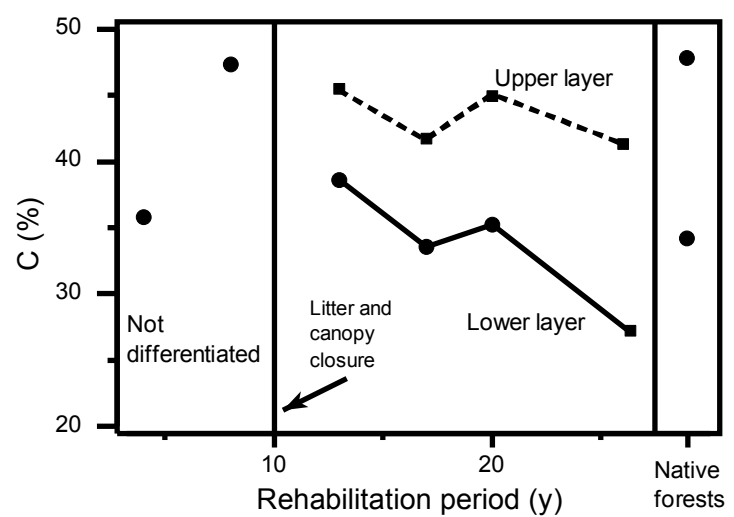

(f)

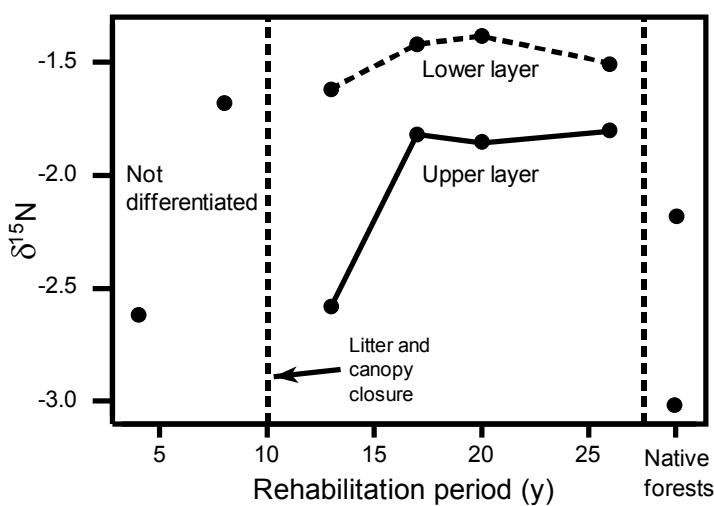

Figure 2 Litter properties in the rehabilitated and unmined native forest soils: (a) Percentage surface coverage of litter, late dry season 2002; (b) Seasonal changes in dry mass; (c) Ranked representation of foliar litter composition: higher ranks imply greater surface coverages; (d) Litter C concentration (\%); (e) Litter C: $\mathrm{N}$ ratio. $(\mathrm{n}=10)(\mathrm{e}) \delta^{15} \mathrm{~N}$ values in litter layers $(\%)$

These permeable soils are also non saline ( $\mathrm{EC}_{[1: 5 \text {, water] }}$ range 0.01 to $0.07 \mathrm{dS} \mathrm{m}^{-1}$ over all sola) and no reduction in growth due to salinity is likely (Marcar and Crawford, 2004). They are also non-sodic: the exchangeable $\mathrm{Na}^{+}$percentage was less than $5 \%$ over all sola, although slightly higher values occurred in some mine floor locations. These data imply that clay dispersion, crust formation and tunnel erosion are unlikely in these landscapes (Field et al., 1997). Cation exchange capacity is low in these soils but increases with soil organic matter concentration (Figure 4a). 
Low $\mathrm{P}$ and $\mathrm{N}$ concentrations commonly limit the productivity of highly-weathered soils. Total $\mathrm{P}$ concentrations in the unmined native forest soils ranged from 168 to $258 \mathrm{mg} \mathrm{kg}^{-1}$ over all except some very shallow profiles. These concentrations are low, even by Australian standards, and it is probable that mature natural ecosystems - which have developed evolutionary strategies to deal with this - are highly conservative of this element. However, it is highly likely that additional $\mathrm{P}$ is required to promote early plant growth post-rehabilitation and redress the dilution and losses that result from mining-associated disturbance. In contrast, $\mathrm{N}$ is largely supplied by biological fixation processes, especially where (as at Gove) leguminous species form a regular part of the rehabilitated plant communities. Total $\mathrm{P}$ concentrations were notably higher (range 140 to $511 \mathrm{mg} \mathrm{kg}^{-1}$ ) in the $0-12 \mathrm{~cm}$ of the profiles of the rehabilitated sites than at greater depths (Figure 4b) and concentrations in this range increased with rehabilitation period (see also Reddell et al., 1993). Concentrations of total $\mathrm{P}$ were strongly positively correlated with those of total $\mathrm{C}$ and Fe.

(a)

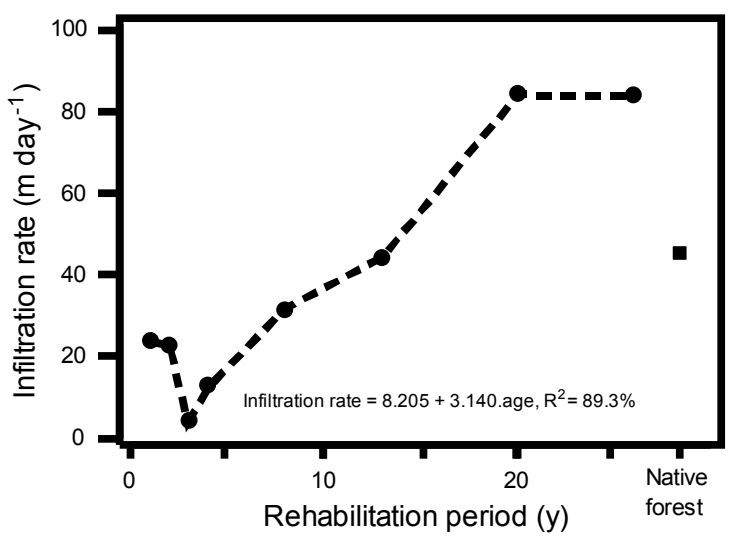

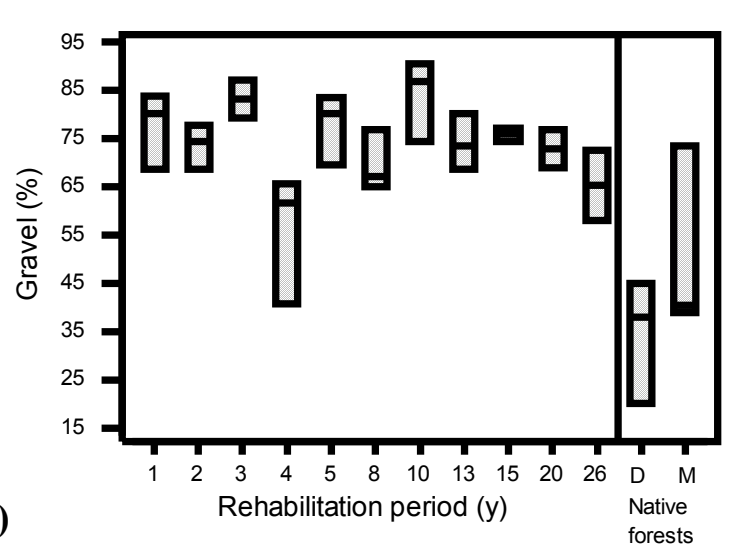

(b)

Figure 3 Soil physical properties: (a) Changes in mean infiltration rate with rehabilitation period; (b) Gravel contents (medians, interquartile ranges) of the restored and two unmined native forest soils ( $D$ deep, $M$ medium profile)

Total P was fractionated (modified Hedley fractionation) into short-, medium- and long-term-available components (Figure 4c). These comprised, respectively, mean values of 1,12 and $18 \%$ of total $\mathrm{P}$ over all sola and the balance was composed of an unavailable residual $\mathrm{P}$ component. The short- and medium-termavailable $\mathrm{P}$ fractions were dominated by their organic components while long-term-available $\mathrm{P}$ was dominated by its inorganic component. Concentrations of all three fractions were greater in the surface than in the underlying soils and concentrations in the rehabilitated soils were significantly greater than those of the native forests for short- and long-term-available fractions but not for the medium-term-available P. From studies conducted elsewhere (e.g., Short et al., 1999; Tchienkoua and Zech, 2003), fertilizer P moves into all other fractions including those available for plant uptake.

\subsubsection{Soil organic matter}

In these developing soils, organic matter governs the supply and retention of both nutrient and pedologicallyimportant elements and is a source of energy for soil organisms. Its sequestration and maintenance are thus critical to the long-term fertility of these highly-weathered soil materials. Both the concentration and quality of the soil organic matter present are important: concentrations are discussed here as $\mathrm{N}$ concentrations and quality is reflected in $\mathrm{C}: \mathrm{N}$ ratios, stable $\mathrm{C}$ and $\mathrm{N}$ isotope ratios and other properties.

Soil $\mathrm{N}$ concentrations at seeding were less than $0.05 \%$. They increased in the upper solum throughout the chronosequence of sites to the point where concentrations substantially exceeded those of the native forest site (Figure 4d); no equivalent increases were apparent below $12 \mathrm{~cm}$. Concentrations in the upper $1 \mathrm{~cm}$ of the upper solum were clearly higher than those immediately below (Figure 4d).

Changes in soil organic matter quality were assessed as the $\mathrm{C}: \mathrm{N}$ ratio, a measure of soil organic matter mineralisation. This value declined from 24 to 16 during the first four years following seeding, reflecting the mineralisation of soil organic matter transported with the soil. With increasing sequestration of plant-derived organic materials, the $\mathrm{C}: \mathrm{N}$ ratio rose to c. 22 in the near surface layers of the longer-rehabilitated sites although near-surface values remained lower than those of the native forest site. Changes in organic matter 
quality are also reflected in the declining $\delta^{13} \mathrm{C}$ values of the surface $(0-5 \mathrm{~cm})$ soils (Figure $4 \mathrm{e}$ ) as $\mathrm{C}$ inputs change from domination by grasses ( $\mathrm{C} 4$ plants) to trees and shrubs (C3 plants). Similar declines in $\delta^{15} \mathrm{~N}$ values (Figure $4 \mathrm{f}$ ) occurred with increasing rehabilitation period, reflecting the greater humification of the soil organic matter.

\subsubsection{Biological fertility}

Biological fertility is that component of fertility due to the activities of organisms. It is reflected in the changing organisation of the surface soil due to the action of the larger soil animals, principally termites. It is also reflected in the activities of soil micro-organisms, most of which are involved in decomposing the organic materials of the litter layers and soil and are therefore major controlling agents of ongoing chemical fertility. Other micro-organisms assist in nutrient acquisition by fixing gaseous $\mathrm{N}$ while mycorrhizal fungi aid plant acquisition of nutrients and water that would otherwise be unavailable to them.

Termites are important soil modifiers and initial decomposers of dead plant materials; they are ubiquitous in the post-mining environment beyond the first few years after seeding. Their presence is evident in the network of galleries apparent in the surface soils and in their occasional mounds. Figure 5a presents an index of the activity of wood-feeding termites (consumption of paper baits), which indicates an activity level equivalent to that of the native forest soils at sites rehabilitated for periods longer than two years.

The activities of decomposer micro-organisms are important indicators of nutrient cycling. Figure $5 \mathrm{~b}$ illustrates the rapid increase in the surface-soil $(0-5 \mathrm{~cm})$ microbial biomass $\mathrm{C}$ concentration to values only slightly below those of the native forests. Figure $5 \mathrm{c}$ presents the activity of chitinase, a soil enzyme important in the cycling of $\mathrm{N}$. The activities of this and other soil enzymes (acid phosphatase, $\beta$-glucosidase, sulfatase, protease and phenol oxidase) measured in these soils followed similar patterns of increase and had values similar to those of the unmined local forests at the longer rehabilitated sites.

The arbuscular mycorrhizal fungi characteristic of grasses, forbs and many juvenile trees and shrubs colonised plants within the first year following sowing, although notable presence of the ectomycorrhizal fungi largely associated with the eucalypts was not found until the third year (Reddell et al., 1992). The incidences of both types continued to increase throughout the 16-year chronosequence of sites then available. Figure $5 \mathrm{~d}$ presents the incidences of three morphotypes of ectomycorrhizal fungi sampled from the root tips of eucalypts in the rehabilitated and native forest sites. There was a complex pattern of morphotype representation: the incidences of some groups rose, others declined and others yet rose and then declined. Some morphotypes appeared or disappeared part way through the chronosequence. Patterns of representation for the rehabilitated sites were substantially different from those of the native forests.

\subsection{Stages of Development}

Integration of the information gained allows the recognition of a number of overlapping stages that extend from earliest establishment to the longer phase of maturation.

The establishment phase lasts for $\mathrm{c}$. three years: grasses are dominant together with some ruderal species and surface coverage by shrubs and small trees is low. Litter cover is initially sparse and the surface unstable, with local erosion occurring into riplines and other depressions. During this phase, the surface becomes stabilised by a surface layer of small gravel-sized particles (pisolites) and the developing cover of herbaceous vegetation and litter. Initial colonisation by social insects and mycorrhizal fungi occurs. Soil organic matter concentration remains low and its $\mathrm{C}: \mathrm{N}$ ratio declines.

The early development stage lasts up to canopy closure (c. 10 years) and is a period of increasing shrub and tree coverage. Grasses are initially dominant but decline and a transient phase of Acacia dominance occurs. Litter coverage continues to increase and then largely closes to form a layer rich in Acacia phyllodes. The soil surface is stable with a mat of fine roots at and close to the surface. The proportion of grass roots to those of dicotyledonous species alters in favour of the latter group (Reddell et al., 1992). Soil organic matter continues to accumulate rapidly and to change in quality, with clear declines in $\delta^{13} \mathrm{C}$ and $\delta^{15} \mathrm{~N}$ values. 

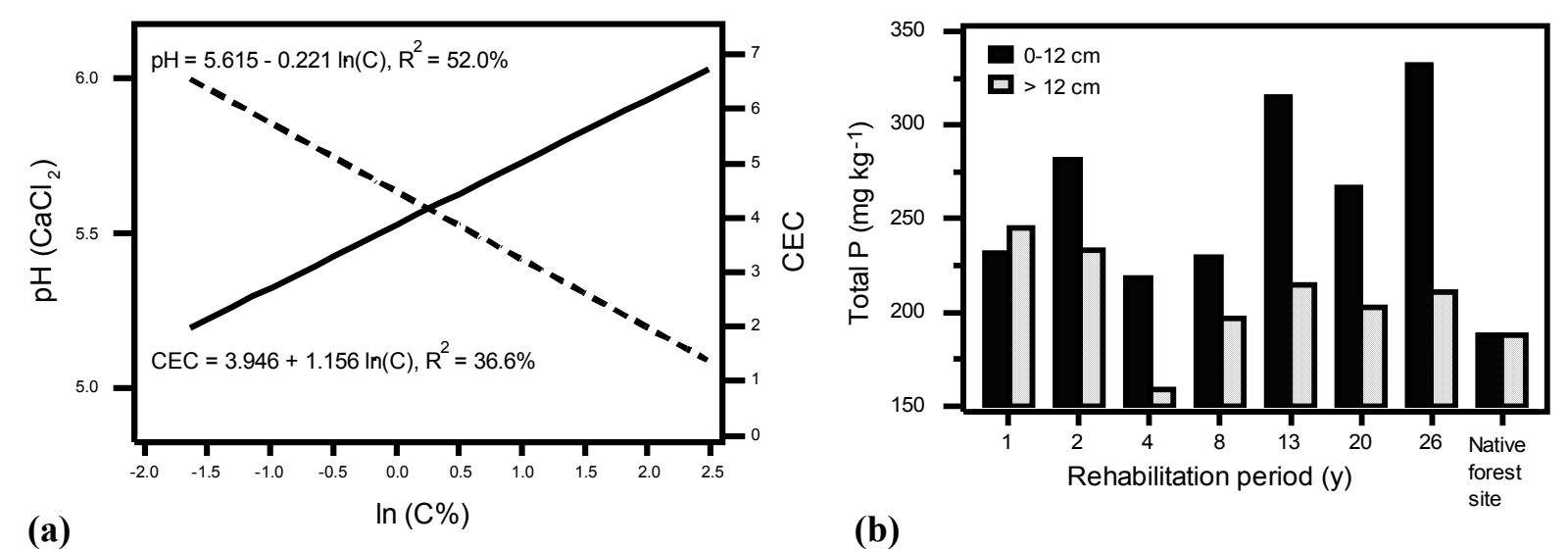

(a)

(b)

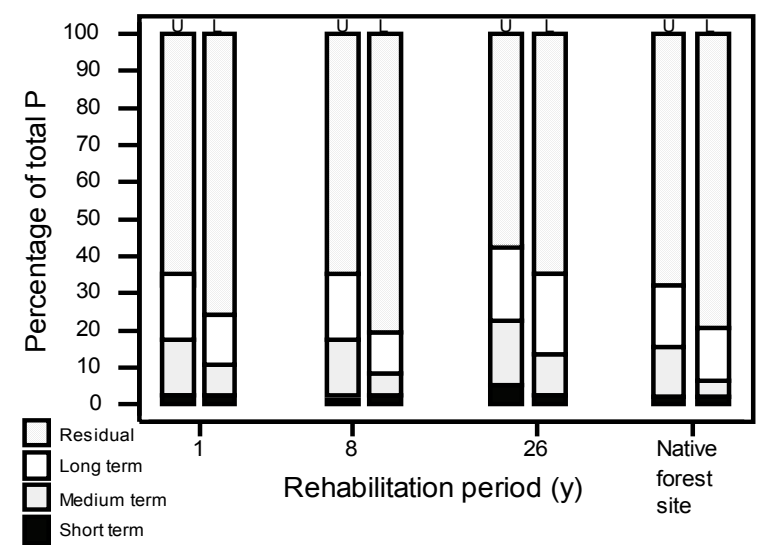

(c)

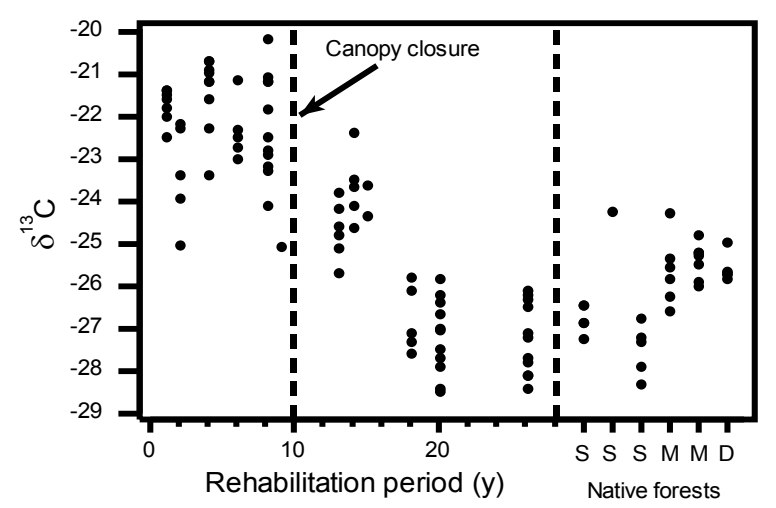

(e)

Figure 4 Soil properties: (a) Relationships of $\mathrm{pH}$ and CEC (cmol kg-1) with In[C]; (b) Mean total $P$ concentrations in the $0-12 \mathrm{~cm}$ layer and the lower profile; (c) Short-, medium-, long-term-available and residual $P$ concentrations in the 0-12 $\mathrm{cm}$ interval $(\mathrm{U})$ and the remaining lower $(L)$ profile of restored and unmined native forest soils; (d) Fine-scale resolution of $\mathrm{N}$ concentration in the upper profile; (e) Variation in $\delta^{13} \mathrm{C}$ values $(\%)$ of the surface $(0-5 \mathrm{~cm})$ soils associated with the change in the dominant inputs of organic matter from grasses to trees (native forest profiles: S shallow, M medium, D deep); (f) Variation in $\delta^{15} \mathrm{~N}$ values $(\%)$ of the surface $(0-5 \mathrm{~cm})$ soils associated with the increasing humification of soil organic matter with rehabilitation period (native forest profile depths as for (e) 


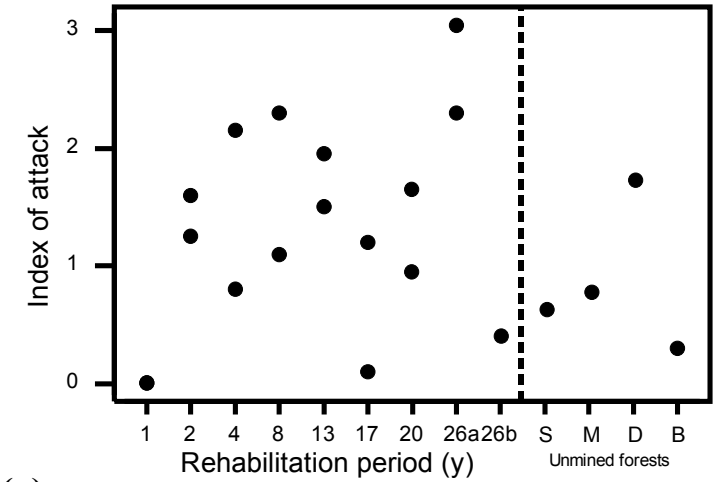

(a)

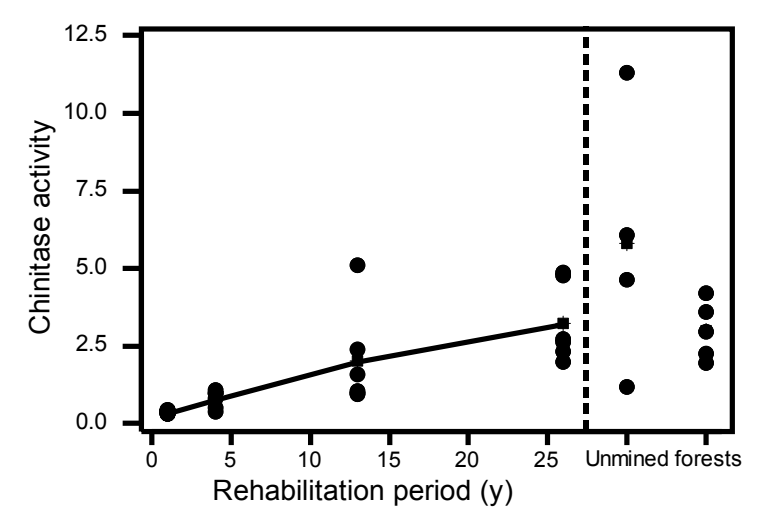

(c)

\section{Figure 5}

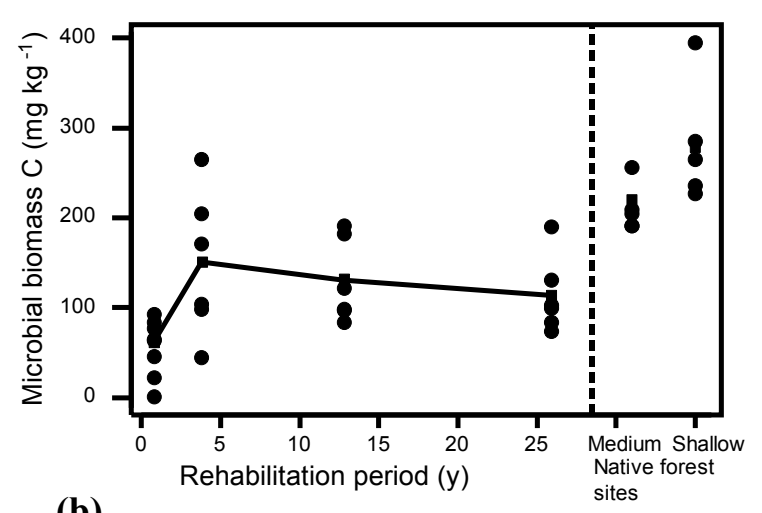

(b)

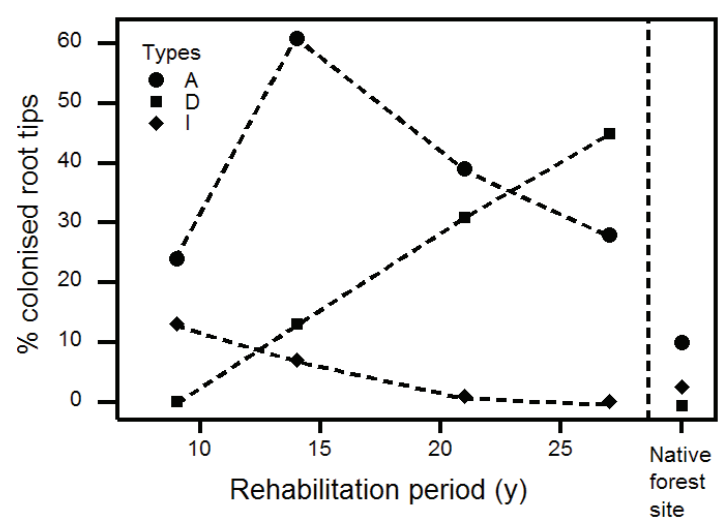

(d) The development of biological fertility in restored and unmined native forest
soils: (a) Termite attack on paper baits - an index of their activity; (b)
Microbial biomass C; (c) Chitinase activity; (d) Changing pattern of
representation of three ectomycorrhizal fungal morphotypes

The third stage is one in which woodland conditions develop and lasts to c. 20 years. It is a period of increasing dominance by eucalypts and decline of the acacias, with a sparse grass growth. The accumulated litter continues to increase in mass and thickness and becomes differentiated into layers. Exploration of the decomposing lower litter by networks of fine roots and fungal hyphae develops. Below the surface, soil organic matter continues to increase and its quality to change with increasing dominance by the broadleaved $\mathrm{C} 3$ plants; this is reflected in its declining $\delta^{13} \mathrm{C}$ status. A network of near-surface large roots develops.

The final stage recognised during the present study is the start of a long period of maturation beyond c. 20 years. It is probable that, over time, the plant community will develop a more open structure. The litter layers and the organic matter of the surface soil appear to be developing towards a possible quasi-equilibrium: the rates of increase of litter layer mass and surface soil organic matter concentrations are in decline and at least some organic matter properties appear to be close to those of the unmined native forests. Rates of increase in infiltration rates appear be slowing over the period of observation and may indicate a developing maturity in soil structural properties.

\section{CONCLUDING REMARKS}

From the information presented above, the successful rehabilitation at the Alcan Gove mine that casual observers might see is underpinned by a very wide range of scientific information expressed in terms of trajectories and rates of ecosystem (including soil) development. This occurs through an overlapping series of stages, each with a characteristic set of ecosystem processes; these lead over time to self-sustainability and resilience in the face of such inevitable threats as fires and storms. Although incomplete in a number of areas 
(notably with respect to the effects of fire on ecosystem development), the information reported here is internally consistent across the disciplines of soil physics, chemistry and biology and complements the informing capacity of vegetation survey. The strength of such a multidimensional and integrated approach lies in its capacity to allow the identification and correction of any deviation from a steadily-improving rehabilitation trajectory. The robustness of this strategy should provide considerable reassurance to stakeholders.

Ecosystem development at Gove is also amenable to rapid, inexpensive monitoring of landscape function processes. Independent work by Tongway and Hindley (2003), using Landscape Function Analysis showed that indices of landscape function provided by this monitoring procedure accurately reflected the processes reported here, thereby providing a verification of the method for this and similar mining operations.

\section{ACKNOWLEDGEMENTS}

We thank Alcan Gove for permission to publish the present information.

\section{REFERENCES}

Bevege, D.I. (1978) Biomass and nutrient distribution in indigenous forest ecosystems. Technical Paper No. 6, Department of Forestry, Queensland.

Field, D.J., McKenzie, D. and Koppi, A.J. (1997) Development of an improved vertisol stability test for SoilPak. Australian Journal of Soil Research, 35, pp. 843-852.

Hinz, D.A. (1992) Bauxite mining and Walyamirri, the return of the living environment, paper two, the rehabilitation programme. Australian Mining Industry Council, Seventeenth Annual Environmental Workshop, Yeppoon, Queensland, 5-9 October, 1992, pp. 102-114.

Kabata, A. and Kabata-Pendias, H. (2001) Trace Elements in Soils and Plants, 3rd edition, CRC Press, Boca Raton.

Marcar, N.E and Crawford, D.F. (2004) Trees for Saline Landscapes. Rural Industries Research and Development Corporation, Kingston, ACT.

Odum, E.P. (1969) The strategy of ecosystem development. Science, 164, pp. 262-270.

O'Keefe, D. (1992) Bauxite mining and Walyamirri, the return of the living environment, paper one, the mining operation. Australian Mining Industry Council, Seventeenth Annual Environmental Workshop, Yeppoon, Queensland, 5-9 October, 1992, pp. 88-99.

Reddell, P., Spain, A.V., Milnes, A.R., Hopkins, M., Hignett, C.T., Joyce, S. and Playfair, L.A. (1992) Bauxite mining and Walyamirri, the return of the living environment, paper three, indicators of ecosystem recovery. Australian Mining Industry Council, Seventeenth Annual Environmental Workshop, Yeppoon, Queensland, 5-9 October, 1992, pp. 115-127.

Reddell, P., Spain, A.V., Milnes, A.R., Hopkins, M., Hignett, C.T., Joyce, S. and Playfair, L.A. (1993) Indicators of ecosystem recovery in rehabilitated areas of the open strip bauxite mine, Gove, Northern Territory. Unpublished CSIRO Minesite Rehabilitation Research Program report to Nabalco Joint Venture, 166 p.

Short, T.A., Menzies, N.W. and Mulligan, D.R. (1999) Mining disturbance alters phosphorus fractions in northern Australian soils. Australian Journal of Soil Research, 38, 411-421.

Spain, A.V., Hinz, D., Ludwig, J., Tibbett, M. and Tongway, D. (2005) Ecosystem development after bauxite mining in northern Australia: processes, patterns of development and the achievement of rehabilitation targets. Proceedings of the 1st International Forum on the Ecological Construction of Beijing. Beijing, 26-27th October, 2005, pp. 164-169.

Tchienkoua, M. and Zech, W. (2003) Chemical and spectral characterization of soil phosphorus under three land uses from an Andic Palehumult in West Cameroon. Agriculture, Ecosystems and Environment, 100, pp. 193-200.

Tongway, D. and Hindley, N. (2003) Indicators of ecosystem rehabilitation success, stage 2: verification of EFA indicators, final report, http://www.cse.csiro.au/research/efa/.

Williams, R.J., Griffiths, A.D. and Allan, G.D. (2002) Fire regimes and biodiversity in the savannas of northern Australia. Flammable Australia: The Fire Regimes and Biodiversity of a Continent, Braddock, R.A., Williams, J.E. and M.A. Gill (eds), Cambridge University Press, Cambridge, pp. 282-304. 